\title{
AS MUDANÇAS EDUCATIVAS PROPORCIONADAS PELAS POLÍTICAS DE AVALIAÇÃO
}

\author{
LOS CAMBIOS EDUCATIVOS PROPORCIONADOS POR LAS \\ POLÍTICAS DE EVALUACIÓN
}

\author{
EDUCATIVE CHANGING PROVIDED BY EDUCATIONAL EVALUATION \\ POLICIES
}

\author{
Correia Paulino SANTOS ${ }^{1}$
}

\begin{abstract}
RESUMO: O tema da avaliação das politicas educativas apresenta uma trajetória bastante rica, tal como refletem os estudos efetuados por diferentes organismos, nomeadamente, a OCDE e a UNESCO, assim como a abundante literatura nacional e internacional. Este artigo, a partir do histórico do desenvolvimento dos processos de avaliação da educação nas últimas duas décadas, considera as conceções académicas sobre a avaliação no contexto da globalização, tendo em conta, particularmente, as propostas teóricas, de alguns autores. Através de uma análise mais pormenorizada das metamorfoses educativas propiciadas pelas políticas de avaliação no espaço educacional Europeu e em Portugal, no contexto da globalização. Também, busca mapear e discutir as novas ações legislativas apresentadas, pelo desenvolvimento das Politicas Educativas e de Avaliação na União Europeia e em Portugal, fazendo uma análise sincrónica e diacrónica das mesmas. Apesar de acentuada aceleração do processo de construção do espaço educativo europeu, Portugal não consegui atingir os resultados que pretendia alcançar, em diferentes domínios.
\end{abstract}

PALAVRAS-CHAVE: Globalização. Educação. Politicas Educativas. Avaliação.

RESUMEN: El tema de la evaluación de las políticas educacionales presenta una trayectoria bastante rica, tal como reflejan los estudios realizados por diferentes organismos, particularmente, la OCDE y la UNESCO, así como la abundante literatura nacional e internacional. Este artículo, desde el histórico del desarrollo de los procesos de evaluación de la educación en las últimas dos décadas, considera las concepciones académicas sobre la evaluación en el contexto de la globalización, llevando en cuenta, particularmente, las propuestas teóricas, de algunos autores. A través de un análisis más pormenorizado de las metamorfosis educacionales promovidas por las políticas de evaluación en el espacio educacional europeo y en Portugal, en el contexto de la globalización. También, busca mapear y discutir las nuevas acciones legislativas presentadas, por el desarrollo de las Políticas Educacional y de Evaluación en la Unión Europea y en Portugal, por medio de un análisis sincrónico y diacrónico de dichas acciones. A pesar de la fuerte aceleración del proceso de construcción del espacio educacional europeo, Portugal no consigue lograr los resultados que pretendía alcanzar, en diferentes dominios.

PALABRAS CLAVE: Globalización. Educación. Politicas Educacionales. Evaluación.

${ }^{1}$ Doutora pela Universidade de Vigo, Portugal. Email: tjcps@sapo.pt

RIAEE - Revista Ibero-Americana de Estudos em Educação, v. 11, n. 4, p. 1985-1905, 2016. 
ABSTRACT: The theme of evaluation of educational policies presents a trajectory quite rich, as they reflect the studies carried out by different bodies, in particular, the OECD and UNESCO, as well as the abundant national and international literature on this topic. In the last two decades, the history of the development of processes for the evaluation of education provides a lot of information and in this article we consider the academic conceptions on the evaluation in the context of globalization, particularly taking into account the theoretical proposals of some authors; in a more detailed analysis into the educative metamorphoses, made available by the evaluation policies into the European and Portuguese space, in the context of globalization. It also tries to draw and promote the discussion in the new legislative actions presented through the development of Educational Policies and Evaluation in the European Union and in Portugal making simultaneously a synchronic and diachronic analysis. Though the marked acceleration of the construction the European educational space the results that Portugal wanted to achieve in this process have fallen short of expectations since there is a significant delay in its implementation into the different domains.

KEYWORDS: Globalization. Education. Educational Politics. Evaluation.

\section{A Globalização e a Educação - Perspectiva de Análise}

A compreensão de que o mundo educacional está a ser reordenado por diferentes reformas e políticas educativas levadas a cabo nos diferentes países durante a década de 80 e 90 do século XX realçam a crescente vertente da internacionalização dos sistema educativos e, por sua vez, levam a falar da globalização das políticas educativas mercê da influência da comunidade internacional, veiculada nomeadamente através de organizações internacionais OCDE, UNESCO, BANCO MUNDIAL, etc., como no-lo reportam (AZEVEDO, 2000; TEODORO 2001a; ANTUNES 2004a).

No entanto, a globalização não significa homogeneização ou uniformização das práticas e das políticas educativas. Como refere (DALE 2001, cit. por TEODORO. 2001a, p.149), a globalização pode "mudar os parâmetros e a direção das políticas estatais no campo da educação", o que não significa que tenha que se sobrepor as particularidades nacionais. Argumenta ainda o autor que os "efeitos da globalização [...] apresentam-se mais diversos e multifacetados do que homogéneos e uniformes". Green (1997), analisando os processos de globalização dos sistemas educativos nacionais, considera que a interpenetração das políticas educativas não significa os fins dos sistemas educativos nacionais, nem o controlo estatal, mas sim uma crescente internacionalização parcial dos sistemas educativos e uma mudança na forma de regulação estatal, detendo o estado um controlo estratégico sobre os sistemas educativos nacionais.

A globalização é, então, um conceito que procura traduzir a crescente 
interdependência mundial, a nível económico, político e cultural. A sua principal característica é a transnacionalização dos sistemas de produção, a crescente constituição das organizações supranacionais, de âmbito global ou regional. É devido aos critérios da globalização que se tem vindo a defender a necessidade de princípios tais como a privatização, a desregulação do mercado educacional, as políticas de livre escolha, a avaliação institucional, o controle de qualidade e aferição da eficácia e a eficiência nas organizações educativas.

No entanto, algumas das configurações teóricas permitem visualizar um complexo de relações sociais e educativas advindas das reestruturações emergentes dos papéis do Estado. As noções de Estado de competição, Estado-em-rede e Estadoarticulador têm vindo a propiciar uma imagem de Estado(s) em que se pode desvendar como, através destas formas de atuação, os Estados reforçam o seu papel de atores principais na formatação de novas formas de regulação social. Esse novo modo de regulação do(s) Estado(s) tem propiciado, precisamente, a emergências de formas concretas de organização dos níveis nacionais e regionais, sendo que, para todos os efeitos, essas formas denunciam os efeitos mais importantes dos processos de globalização. $\mathrm{Na}$ educação, estas mudanças moldam uma "agenda globalmente estruturada em torno da redefinição dos serviços educativos [e de bem-estar] e do papel do Estado na governação da educação" (ANTUNES, 2004a: 81 e ss.).

Para além da educação, como em outros serviços, é assim possível descobrir a promoção de uma nova cultura institucional, fruto do processo de globalização e da crescente internacionalização (mesmo que parcial) dos sistemas educativos e das mudanças de regulação estatais. O nível de linguagem, os discursos produzidos, as ideologias, a ação e as formas de análise são transportados do setor público privado empresarial para o sector educativo público. Esta nova cultura institucional tem a particularidade de assentar em dois vetores: o "universalismo" e o "isomorfismo" (TEODORO 2002,p. 67).

\section{A Avaliação no Sistema Educativo da União Europeia}

A avaliação dos sistemas educativos tem vindo a ser estudada como referencial das políticas educativas europeias e nacionais e sujeita a vários modelos de análise. De entre estes, destacamos os de Roggero (2002) que, precisamente num estudo efetuado sobre a avaliação dos sistemas educativo nos países da união europeia, propõe modelos 
de avaliação escolar, nomeadamente, o modelo concorrencial inglês, o modelo de interesse geral francês e o modelo finlandês - o compromisso entre a eficácia e a igualdade.

Estes três modelos encarnam modelos de avaliação típicos nas suas modalidades e inspirações. Quanto ao modelo de avaliação inglesa "externalizada mesmo privatizada " numa lógica de eficiência em que se encontra associada a uma regulação mercantil. A avaliação interna no modelo Francês é centralizada e predomina "a primazia da escola Republicana no modelo de interesse geral". Por último o modelo finlandês "pluralista e consensual, traduz a capacidade de inscrever a lógica da eficácia no quadro comunitário alicerçada na legalidade" (ROGGERO, 2002, p.37).

Destacamos a perspectiva de Hadji (2010, p.114-117) relativa à situação educativa francesa e as importantes mudanças ocorridas na escola, que em nossa opinião se prolongam por outros países da União Europeia, nomeadamente em Portugal. A mudança do público-alvo, a massificação da população escolar, ou seja, um aumento da duração da escolarização, um número de alunos cada vez maior, escolarizados durante mais tempo e de origens socioeconómicas cada vez mais diversas. Por sua vez as mudanças nos comportamentos escolares, num contexto de desacreditação e desvalorização da escola.

Com a tendência na Europa para a descentralização, ampliou-se a sensibilidade à avaliação no campo educativo. Por outro lado, as organizações educativas cada vez mais responsáveis por sua ação encontram meios de conhecer em profundidade os resultados da avaliação. A avaliação responde ao mesmo tempo a uma procura de transparência e de informação sobre os Sistemas Educativos emanadas das famílias, das empresas e das coletividades públicas que sentem necessidade de pilotagem e de regularização.

Os três modelos referidos anteriormente não representam a totalidade dos sistemas de avaliação na União Europeia, como nos refere o autor. No entanto, as políticas de avaliação na União Europeia deixam perpassar indícios da presença de todos eles, sendo de destacar o modelo finlandês apresentado, uma vez que defende a apresentação de um conjunto de indicadores relativos à eficácia dos estabelecimentos, responsabilidade financeira e os resultados escolares e culturais obtidos e, ainda, o modelo Inglês pelo destaque que dá a uma cultura de avaliação em que tudo é medido com base na regularização feita pelo mercado. Para melhor percebermos estas ideias, tenhamos em consideração o desenvolvimento das políticas educativas relativas à avaliação que, de seguida, sucintamente apresentamos. 
A educação emerge como campo de ação a nível comunitário em 1971, com a criação pela Comissão Europeia de dois grupos de trabalho, um para o Ensino e Educação e outro para a Coordenação. Na década de 70 é possível sinalizar preocupações e iniciativas comunitárias no domínio da "cooperação no âmbito da Educação", designadamente no que se refere a algumas "esferas de ação prioritárias: maiores possibilidades de formação cultural e profissional para migrantes e seus filhos; melhoramento da correspondência entre os sistemas educativos da Europa [...]" (CCE, 1988, p.16).

Rodriguez (1993) considera, a nível da "cooperação comunitária em educação", um primeiro período entre 1957-1976, sendo que "a lentidão dos primeiros passos", de 1976 a 1986, é caracterizada pela emergência de "uma nova perspetiva de cooperação em educação", seguida pelo alargamento das competências das instituições comunitárias e pela supressão de fronteiras entre a educação e a formação profissional. Salienta Rodriguez (1993, p. 7-13) "que a inclusão da referência a favor da integração escolar dos deficientes e da luta contra o analfabetismo são os traços marcantes daquela nova perspetiva".

Considerando o projeto de integração dos estados-membros, nos anos oitentas, o crescimento, a valorização da interdependência dos estados soberanos, em substituição da mera cooperação, na procura de afirmar uma representação da Europa entre os cidadãos, tentando superar a imagem tecnocrática e economicista que até então prevalecera, a Comunidade Europeia desejou, a partir de então, potenciar o espírito europeísta, recorrendo para isso a propostas no domínio cultural e educativo, com a livre circulação das pessoas e de bens e a noção de cidadania. A criação da União Europeia culturalmente guiada pela ideia de unidade na diversidade, mais propriamente a europeicidade, é então definida por um conjunto de significados selecionados de diferentes culturas europeias. A forma como este processo tem lugar é condicionada pelo impacto da globalização nas coordenadas de espaço e tempo, que determinam em grande parte como é a identidade europeia, localizada e representada.

No período entre 1986 e 1992 surge, então, uma inovação baseada no aparecimento de Programas de Acão comunitários na área da educação. Tais Programas de Acão são adotados após a assinatura do ato Único Europeu em fevereiro de 1986.

Antunes (2004a, p.129-141) destaca como inovações importantes da educação na Comunidade Europeia, entre 1971 a 1992, dois períodos relevantes: O primeiro que vai de 1971 a 1986 com: 
[...] a institucionalização da educação como área de acção comunitária: O Conselho Europeu e os Ministros da educação [...] definem entendimentos e assumem acordos de princípio para promover medidas genéricas e pontuais ou projectos pilotos, orientados para objectivos comuns estabelecidos pelos estados membros $[\ldots]$.

O segundo período entre 1986 e 1992 com:

[...] a intervenção política comunitária no domínio da educação: $\mathrm{O}$ Conselho Europeu e os Ministros da educação [...] assumem e promovem [...] Programas de Acção Comunitários orientados para [...] os objectivos que os estados membros determinavam ou seja objectivos comuns [...] assentes em regulamentos comunitários, operacionalizados aos níveis nacionais, transnacional e comunitário por organismos de coordenação e ligação entre os estados membros e a União Europeia.

Retomando a perspetiva da autora, este segundo período distingue-se por uma dinâmica de inovação, em construção progressiva, desenhada e consolidada com base no estabelecimento de agendas e prioridades comuns aos Estados-membros na esfera da educação, assente na cooperação intergovernamental e processos normativos.

Assim, as dinâmicas de europeização e de constituição de um referencial global europeu adotaram uma intervenção, intensidade, amplitude e profundidade e, principalmente, um desenvolvimento associado à expansão do âmbito dos Programas de Acão, a partir de 1994, tais como o Socrates, para a educação, Leonardo Da Vinci, para a formação, Comenius, para promover parcerias transnacionais (ANTUNES, 2005, p. 128).

Há a considerar, ainda, um conjunto de iniciativas que parecem assinalar a emergência de um novo momento deste percurso: o Programa de objetivos comuns para 2010 (1999/2000), posteriormente renomeado Educação \& Formação 2010, o processo de Bruges/Copenhaga (2001/2002), o processo de Bolonha (1999).

Com a adoção de políticas educativas entre os Estados e a circulação do conhecimento especializado, devido ao avanço tecnológico, aceleraram-se e multiplicaram-se as possibilidades globais de comunicação. Além disso, verificou-se a emergência de um potencial inédito consubstanciado na constituição de redes em meio digital que podem agir em simultâneo e de forma concreta. A este propósito (MARCONDES, 2004, p.225) refere que, 'Como a Sociedade da Informação não altera apenas o funcionamento das empresas, mas também delineia a educação e a formação, a União Europeia incentiva o mercado europeu no sector da multimédia educativa [...]'. 
A educação "tem vindo a tornar-se, progressivamente um tema central nos debates políticos, a nível nacional e internacional [...]” (TEODORO, 2002, p. 11). Porém, os efeitos práticos desse projeto estão bem presentes nas políticas educacionais desde o final dos anos noventa em diferentes países, onde se verifica notável similitude de opções assumidas pelos Estados Nacionais. Mas esses efeitos, em países centrais ou pertencentes a espaços centrais, fazem-se sentir, sobretudo, pela fixação de uma agenda global. Despontam novas aspirações para a Europa com os sistemas de educação e de formação nos Estados-membros com vista a uma política educativa europeia. $\mathrm{Na}$ sua reunião de Lisboa, em Março de 2000, o Conselho Europeu (os chefes de Estado e de Governo dos países da UE) reconheceu que a União Europeia se defrontava com uma enorme mudança resultante da globalização e da economia baseada no conhecimento, tendo acordado num objetivo estratégico para 2010. “Tornar-se na economia baseada no conhecimento mais dinâmica e competitiva do mundo, capaz de garantir um crescimento económico sustentável, com mais e melhores empregos, e com maior coesão social" (CE, 2002, p. 7).

Esta preocupação tem-se manifestado pelos relatórios produzidos e estudos emanados de grupos de trabalho constituídos com essa finalidade, sob a tutela da Comissão das Comunidades Europeias. A produção e difusão de grande variedade de documentos sob a forma de pareceres, recomendações, relatórios, conclusões, demonstram a importância que tem sido dada pela União Europeia ao desenvolvimento das políticas educativas que, na sua globalidade, enformam as decisões locais e nacionais comuns aos Estados-membros. Esta enorme variedade de trabalhos ora em forma de livro, ora em forma de brochuras oficiais, ora via Web, têm sido publicados pela Comissão Europeia e difundidos pelos diferentes Estados-membros, por exemplo, em alguns números do Jornal Oficial da União Europeia (JOUE) ou nas páginas da Rede Europeia de Educação - Eurydice.

Com o Tratado de Maastricht em 1992 e, mais tarde, na Cimeira de Lisboa de 2000, o Conselho Europeu estabeleceu a meta de tornar os sistemas de educação e de formação na União Europeia "uma referência mundial de qualidade, até 2010", conduzindo à elaboração de um conjunto de instrumentos de ação pública destinados ao cumprimento desse objetivo político. Plataformas intergovernamentais regionais como o processo de Bolonha apresentam traços comuns e verificam singularidades que estabelecem instâncias de mediação que criam, filtram e veiculam os processos de 
globalização com os quais se pretende mostrar a importância que terá a educação ao longo da vida para transformar a União Europeia num espaço económico competitivo.

Da importância de que se revestiram algumas recomendações daí emanadas, verificamos que se realça a necessidade premente de encontrar respostas para os sistemas educativos de modo a que estes se possam adaptar às exigências económicas num mundo globalizado. Para que tal possa concretizar-se, é posto em marcha um programa de trabalho intitulado Educação e Formação 2010 para cumprir alguns objetivos fulcrais da sociedade do conhecimento, nomeadamente, fazendo da Europa o espaço mais competitivo do mundo até 2010.

No cumprimento dos objetivos do programa que tinha sido em posto em curso, os três domínios de conhecimento prioritários que seriam objeto de trabalho do Conselho de 2002, em Barcelona (e que já vinham do Conselho de Estocolmo de 2001), seriam os que se referiam às competências de base; tecnologias de informação e de comunicação; matemática; ciência e tecnologia. Finalmente, o Conselho de Julho de $2001 \mathrm{fez}$ saber que todos os indicadores reunidos pelos diferentes Estados-membros teriam, à partida, também uma enorme importância para o Conselho de Barcelona, visto serem um instrumento de medida e de comparação dos resultados que, certamente, seriam úteis para as políticas.

Deste modo, numa perspetiva de interação, os Estados membros ficariam comprometidos em disponibilizar informações detalhadas relativamente a dados atualizados no que concerne às mudanças visíveis nas políticas (que influenciariam, no futuro próximo, os sistemas de educação e de formação), à comunicação de informações qualitativas (como, por exemplo, a participação em estudos e a nomeação de especialistas junto dos grupos de trabalho). Por seu lado, a Comissão Europeia iria associar-se a todas as fases do trabalho e tomar as medidas necessárias para o prosseguimento deste processo.

Acrescente-se, ainda, que a avaliação dos sistemas de ensino assume uma grande importância nas recomendações emanadas desta instância, pois, já em 24 de Janeiro de 2000, a Comissão das Comunidades Europeias tinha apresentado uma proposta de recomendação do Parlamento Europeu e do Conselho sobre a cooperação europeia com vista à avaliação do Ensino Básico e do Ensino Secundário, na qual foi sublinhado que, para dar cumprimento a esta prerrogativa, os Estados membros precisariam de criar sistemas transparentes de garantia da qualidade ao incentivar a autoavaliação e a avaliação externa das escolas. 


\section{A Avaliação no Sistema Educativo Português}

A União Europeia tem-se constituído como mediador, veículo e autor de processos de globalização e o Estado português interpretou, aceitou, traduziu e reagiu aos constrangimentos e recursos nacionais conjugando as suas interações (mais ou menos intensas, mediadas ou difusas) com dinâmicas transnacionais e globais (ANTUNES, 2004a).

Desta feita, é importante salientar que a politica educativa europeia, na opinião de (Stoer e Cortesão 1999, p.112), “está entalada entre a ambiguidade de desejar por um lado promover a dimensão europeia da educação [...]" e, ao mesmo tempo, considerar “que a educação é, por definição, o espaço para a construção da identidade nacional”. O problema desta ambiguidade, além do efeito de diluição que tem sobre o conteúdo da dimensão europeia, torna possíveis importantes desmoralizações relacionadas com o desenvolvimento da política educativa.

Numa retrospetiva histórica, pode dizer-se que a evolução da educação, em Portugal, após a instauração do regime democrático, foi dominada pela ascensão e queda de reforma e estende-se de 1986 até final do século XX. Na verdade, a aprovação, em 1986, da Lei de Bases do Sistema Educativo "permitiu fechar o ciclo da normalização da política educativa e abrir uma nova fase, centrada novamente no propósito de realizar a reforma educativa" (TEODORO, 2001b,p. 399). Nesta sequência de análise, BARROSO (2003,p. 70) refere que:

[...] podemos dividir a reforma em dois grandes períodos: o primeiro é protagonizado pelo ministro Roberto Carneiro que integra um governo do Partido Social-Democrata (centro-direita), entre 1987 e 1991; o segundo é protagonizado pelo ministro Marçal Grilo que integra um governo do Partido Socialista (centro esquerda), entre 1996 e 2000.

De entre um conjunto variado de medidas tomadas nesse $1^{\circ}$ período, a reforma ${ }^{2}$ é concebida e desenvolvida segundo um modelo normativo discursivo, fundada numa conceção determinista de mudança através de medidas decretadas tendo em vista assegurar a integração plena de Portugal na Comunidade Europeia.

\footnotetext{
2 As reformas deste período foram no sentido da racionalização do trabalho da escola ao valorizar as tecnologias educativas. Mas se essa opção foi para responder à crise da educação então vivida elas não tiveram sucesso porque a crise perdurou, tendo em conta a continuação dos relatórios críticos sobre o sistema educativo, o que levou a que no final da década de 80 tenha surgido, de um modo geral, uma nova vaga reformadora que valorizava a escola enquanto organização (Sarmento, 1993: 38-39).
} 
Muitas dessas medidas eram destinadas a pôr em prática e a regulamentar a Lei n. ${ }^{\circ}$ 46/86, Lei de Bases do Sistema Educativo, de 14 de Outubro, que vem estabelecer os princípios gerais do sistema de ensino e regula a sua organização estrutural genérica. Surge o Decreto-Lei n. ${ }^{o}$ 172/91, de 10 de Maio, que define o regime jurídico de direção e gestão dos estabelecimentos de ensino que vindo consagrar os níveis de Direção e Gestão dos estabelecimentos de ensino, tenta mobilizar, reforçar e valorizar a tríade Projeto Educativo (PE), Plano Anual de Atividades (PAA) e Regulamento Interno (RI). São de destacar ainda, pelo seu significado político, as seguintes: uma contenção do acesso ao ensino superior público e um forte estímulo à abertura de estabelecimentos de ensino superior privado através do Lei 37/94, de 11 de Novembro e ratificado pelo Decreto-Lei n ${ }^{\circ}$ 16/94; a criação das "escolas profissionais"”3 com o Decreto-lei n. ${ }^{\circ}$ 26/89, de 21 de Janeiro; o reforço de dispositivos da ação social na escola no âmbito das instituições do ensino superior através do Decreto-Lei n. ${ }^{\circ}$ 129/93, de 22 de Abril; a avaliação com o início da avaliação do ensino superior com a Lei n. ${ }^{\circ}$ 38/94, de 21 de Novembro, a criação de um "observatório de qualidade das escolas"4, com a Resolução do Conselho de Ministros n. ${ }^{\circ}$ 29/91, de 9 de Agosto.

O segundo período da reforma decorre entre 1996 e 2000 e corresponde à vigência de um governo do Partido Socialista. Como instrumento essencial dessa política, o ministro apresentou em 1996 ao Parlamento, às escolas e aos diferentes "parceiros educativos" um Pacto Educativo para o Futuro. Contudo, em virtude das condições políticas (governo sem maioria absoluta) e da própria ambiguidade do seu

\footnotetext{
${ }^{3}$ Portaria n ${ }^{\circ}$ 709/92, DR 158, Série I-B, de 1992-07-11 Ministérios das Finanças e da Educação Aprova o modelo de diploma dos cursos profissionais. Portaria $\mathrm{n}^{\circ}$ 423/92, DR 118, Série IB, de 1992-05-22 Ministérios da Educação e do Emprego e da Segurança Social Define o regime de avaliação nas escolas profissionais. Despacho no 22 152/2007, DR 183, Série II, de 2007-09-21 Financiamento público dos cursos profissionais de nível secundário, às escolas profissionais privadas na Região de Lisboa e Vale do Tejo.

${ }^{3}$ De referir, ainda em 2004, que a Universidade de Aveiro e a Universidade do Minho foram duas das onze instituições universitárias europeias que receberam o prémio de implementação do ECTS - ECTS Label - atribuído pela Comissão Europeia.

${ }_{4}$ Este Programa foi criado em 1991, no sentido de promover e assegurar a escolaridade de 9 anos e o acesso com sucesso a uma escolaridade de 12 anos, tendo como principal finalidade "promover a melhoria da qualidade da educação e do ensino [...]" (ponto 1.3 do anexo à Resolução referida). Este Programa é um programa de âmbito nacional que se enquadra nas "[...] Recomendações da Conferência Mundial sobre EDUCAÇÃO PARA TODOS, realizada em 1990 [...], sobre os auspícios da UNESCO, UNICEF, PQNUD, Banco MUNDIAL e da Conferência de Ministros da Educação da OCDE, realizada em 1990, em Paris" (ME, 1993, p. 6) e que se pretendia desenvolver até ao ano 2000. Por outro lado, o aumento do número de escolas que aderiram ao programa logo nos primeiros anos é significativo como se constata no documento " Observatório da Qualidade da Escola. Guião Organizativo", ao referir: "[...] no ano lectivo de 1992/93 contavam-se 50 escolas [...]; no ano de 1993/94 eram já 128 [...]. No ano lectivo de 1994/95 este número subiu para 168" (Clímaco, 1995: 3).
} 
conteúdo, o Pacto não agradou à opinião pública e, assim, este não chegou a concretizar-se.

Nesta sequência, foram tomadas diversas medidas legislativas que deram continuidade à reforma anterior: A nível da autonomia e gestão das escolas, através do Decreto-Lei n. ${ }^{\circ}$ 115-A/98, de 4 de Maio (que inclui nas competências da Assembleia de Escola "apreciar os resultados do processo de avaliação interna da escola") e da Lei $n^{\circ}$ 24/99, de 22 de Abril.

As políticas educativas nacionais, quer no primeiro período da reforma quer no segundo período foram fortemente apoiadas por um substancial reforço financeiro, no âmbito do Quadro Comunitário de Apoio negociado com a Comissão Europeia e que se traduziu no Programa de Desenvolvimento Educativo para Portugal (PRODEP). Esse Programa tinha como objetivo "preparar o sistema educativo português para as exigências económicas e sociais decorrentes do processo de integração europeia”, por intermédio dos seguintes vetores estratégicos: "generalizar o acesso à educação; modernizar as infraestruturas e melhorar a qualidade da ação educativa" (BARROSO 2003, p.72).

Ainda sobre as reformas, Nóvoa (1991, p.52) salienta que, nos anos 80, a grande parte dos países desenvolvidos apontam "orientações que se prolongam na tendência dos anos 60 em favor das ciências, da matemática e da tecnologia, no quadro de uma maior coerência e estandardização dos conteúdos e de uma melhoria significativa dos resultados". Menciona ainda o autor que "As Reformas atuais [...] combinam vários elementos por vezes contraditórios: a descentralização, o apelo à participação, a instauração de novos dispositivos de acompanhamento, a autonomia das escolas, a intervenção das comunidades locais, a necessidade de avaliações, etc.”.

Após a euforia da Reforma em que se empenharam os dois maiores partidos do espectro político português, surge um estudo de reflexão sobre $\mathrm{O}$ futuro da educação em Portugal coordenado por Carneiro (2000, p. 34-35) que assim faz o balanço da situação relativamente ao aumento da escolaridade: "O progresso educativo foi, a muitos títulos, impressionante. A escolarização de crianças e jovens conheceu um desenvolvimento exponencial. (...)". Trata-se de um balanço no qual se pretende contrastar as questões da "quantidade" e da "qualidade", ou seja, o aumento da escolaridade, por um lado, e a taxa de o insucesso escolar, por outro. Este estudo abre para uma perspetiva de desenvolvimento do sistema educativo moldado no objetivo de "recuperar o atraso que nos separa dos nossos parceiros europeus". Teodoro (2001a, p. 
146), ao reportar-se aos desafios que Portugal enfrentou aquando da sua integração europeia, afirma poder ser possível estabelecer uma relação entre a melhoria da qualidade de ensino, a reforma educativa portuguesa.

Alguns autores, nomeadamente Afonso (1998, 2001); Santos (2001); Teodoro (2001) e Canário (2005) chamam a atenção para as sucessivas crises da educação pública, em tempo de globalização, que acaba por produzir algumas fragilidades ao nível das decisões de política educativa. Algumas estatísticas europeias (Eurydice e Eurostat, 2002) também acabam por ilustrar os défices de conhecimentos científicos e técnicos que, persistentemente, acompanham os alunos portugueses ao longo do Ensino Básico e do Ensino Secundário. Ora, esses mesmos défices de aprendizagem e de conhecimentos não se combinam com as necessidades imperiosas da competitividade económica e com as lógicas globais da sociedade de mercado. Sobressai a grande preocupação do governo de adotar algumas estratégias para combater o défice educativo, as desigualdades face à escolarização e diminuir a exclusão social da sociedade portuguesa. Deste modo, a educação passa a ser encarada como uma "prioridade efetiva" que elege, entre outros aspetos, a campanha contra o abandono precoce dos jovens do sistema de educação/formação sem qualquer qualificação.

Embora a competitividade educacional seja uma preocupação de Portugal, como muitos outros países, inspiradas pelas reformas dos governos. O crescimento da competitividade internacional no domínio da educação é o desenvolvimento e a utilização dos dados do PISA (Programme for International Student Assessment), que é um dos programas mais conhecidos, junto da opinião pública, para salientar os fracos níveis de aproveitamento escolar. Programa internacional de avaliação dos alunos, da OCDE, que para alguns, representa a "promoção de uma politica neoliberal através da avaliação educativa “(Uljens, 2007, cit. por Day 2010,p. 148). Apesar das críticas às suas metodologias os governos continuam a participar e a avaliar o progresso educacional das suas escolas em função das suas posições no ranking do PISA (Day, 2010,p. 148). A este propósito Hopmann (2007, p.364) considera que:

Aquilo que tem mais valor aos olhos do público não são as técnicas de investigação (...), mas as mensagens simples que caracterizam a aparência pública do PISA: os rankings e os resumos, indicando aquilo que o Pisa encara como os pontos fracos e fortes dos respectivos sistemas de ensino. 
Para Hopmann (2007, p.367-372), o crescimento do PISA deve-se, em grande parte, à era da "prestação de contas", na qual os governos se esforçam por "redistribuir recursos, riscos e responsabilidades dentro das e através das próprias sociedades". É uma nova era caracterizada pela definição e imposição de objetivos definidos pelo sistema e pela "gestão das expectativas".

Deste modo, perante o atraso educativo em que Portugal se encontrava no início do século XXI, havia que proceder à aceleração de todo o processo para atingir metas definidas pela União Europeia, e impostas aos diversos Estados-membros, também eles em atraso relativamente a exigências globais.

Recorde-se que de acordo com os dados do Recenseamento da População Portuguesa em 2001, a taxa de abandono na escolaridade obrigatória rondava os 3\%, a população do grupo etário $18-24$ anos que não concluiu o $9^{\circ}$ ano atingia os $25 \%$ e a população do mesmo grupo etário que não concluiu o Ensino Secundário rondava os $45 \%$. Assim, "em termos concorrenciais, no quadro da EU, basta recordar que o país que está mais próximo de nós em taxa de não conclusão do Ensino Secundário, entre a população mais jovem, é a Espanha, com uma taxa de $29 \%$ (contra os nossos 45\%) muito longe da média na União de 19\%" (AZEVEDO, 2003, p.57-58).

Graça (2009, p. 50-80) refere que "Esta aceleração do processo de construção do espaço educativo europeu comportou aspetos contraditórios, propiciou tensões diversas e provavelmente, até 2005, não terá logrado alcançar os resultados pretendidos", nomeadamente em Portugal. Reforça esta posição com os resultados do PISA, para além do ranking que certamente não é o que melhor ajuda a compreender a realidade educativa portuguesa, é de salientar que o PISA evidencia que existe uma forte influência do "Estatuto Sócio Económico Cultural" (ESEC) dos alunos nos resultados académicos por estes obtidos.

O Gabinete de Avaliação Educacional do Ministério da Educação (GAVE) (2004), na análise que produziu sobre os resultados do PISA 2003, alertava para as implicações do baixo (ESEC) dos alunos portugueses bem como para o facto do nível de despesa por aluno português ser inferior ao de outros países.

Existe uma associação positiva entre o desempenho médio dos alunos de cada país e o rendimento nacional ou o gasto por aluno nesse país. Se ajustássemos o desempenho médio de cada país àquele que seria de esperar se as condições sociais e económicas fossem médias, Portugal melhorava substancialmente a sua posição relativamente aos restantes participantes. 
Ora, relativamente a Portugal podem-se constatar, no referido PISA 2006, vários indicadores muito interessantes ${ }^{5}$ para se compreender o desempenho dos alunos portugueses e até o papel da Escola portuguesa. A este propósito, veja-se que relativamente ao abandono escolar precoce, cujo valor de referência para 2010 é ficar abaixo de 10\%, Portugal apresentava, em 2000, o valor de 42,6\% e, em 2006, o valor de $39,2 \%$. A sua evolução, nestes seis anos, foi inferior à evolução média da União Europeia, apresentando-se como um dos países com piores resultados (apenas Malta apresentava piores resultados mas com uma evolução mais rápida). No que respeita à conclusão do ensino secundário, o valor de referência para 2010 é de $85 \%$, mas Portugal encontra-se muito longe dessa meta. Em 2000, a sua percentagem de conclusões do ensino secundário era de 43,2\% e, em 2006, passou para 49,6\%, sendo este o pior resultado da União Europeia. Quanto à participação em ações de aprendizagem ao longo da vida, o valor de referência para a União Europeia, em 2010, é de 12,5\%. Portugal apresentava o valor de 3,4\% em 2000, e de 3,8\% em 2006.

Digamos, pois, que Portugal, no que com cerne ao cumprimento dos objetivos para a educação e formação estabelecidos pela União Europeia, contribui de uma forma negativa uma vez que existe um significativo atraso na sua concretização em muitos domínios.

Atualmente persistem os problemas, com destaque, ainda, para o abandono e o insucesso escolar e os fracos resultados escolares dos estudantes portugueses evidenciados pelos instrumentos internacionais de aferição. De acordo com um relatório da União Europeia, Portugal surge como um dos países europeus, onde menos alunos completam o secundário. O documento revela que Portugal e Malta são os piores no que refere ao abandono escolar, com taxas de 36,3\% e 37,6\%, respetivamente em 2007.

\footnotetext{
${ }^{5}$ Vasco Graça (2009: 50-80) diz: Primeiro, o ESEC dos alunos explica uma percentagem elevada dos resultados obtidos pelos alunos portugueses. Em Portugal, o ESEC explica 16,6\% resultados, enquanto a média da OCDE é de $14,4 \%$. Por exemplo, na Coreia, o ESEC explica apenas $8,1 \%$ dos resultados, enquanto no Reino Unido explica $13,9 \%$, na Dinamarca explica $14,1 \%$ e nos EUA explica 17,9\%. Esta influência explicativa do ESEC é forte, mas, por si só, não é o único aspeto sócio-económico-cultural a ter em consideração. Segundo, a percentagem dos alunos portugueses, que se situa nos $15 \%$ inferiores da distribuição do ESEC, é muitíssimo elevada, 43,5\%, quando a média da OCDE é 17,9\%. Ou seja, uma parte muito elevada dos alunos portugueses tem um ESEC bastante baixo. Terceiro, o PISA 2006 fornece um outro indicador relativo ao ESEC dos estudantes bastante curioso. Este Programa Internacional de Avaliação procura estabelecer uma relação estatística entre o escalonamento sócio-económico-cultural dos alunos e os resultados académicos por si obtidos. Ou seja, precisa, para cada país, quanto é que se reflete nos resultados académicos cada ponto de diferença sócio-económico-cultural.
} 
Vejamos, agora, também, alguns diplomas que revertendo ou não diretamente sobre a avaliação, indiretamente alteram as políticas educativas, convergindo nas diretrizes emanadas da União Europeia.

Assim, a nível da retenção, com o Despacho Normativo $n^{\circ} 50 / 2005^{6}$ clarifica a retenção como medida de exceção:

- A nível certificação das aprendizagens realizadas pelo aluno no ensino básico, com o Despacho Normativo ${ }^{\circ}$ 6/2010 de 19 de Fevereiro, com as Alterações ao do decreto-Lei n. ${ }^{\circ}$ 6/2001, de 18 de Janeiro, nos termos do n. 6 do artigo $12 .^{\circ}$, com as alterações introduzidas pelo Decreto-Lei n. ${ }^{o}$ 209/2002, de 17 de Outubro. No sentido de acionar todos os mecanismos de intervenção que possibilitem o reforço dos instrumentos de inclusão e prevenção do abandono escolar, com vista a tornar exequível a frequência de ensino para todos os jovens até aos 18 anos e que as escolas possam, no quadro de desenvolvimento da sua autonomia, tomar decisões sobre o processo de avaliação dos seus alunos.

- A nível da "avaliação externa" e da "autoavaliação" das escolas não superiores através da Lei $n^{0} 31 / 2002$, de 20 de Dezembro, designada por "Lei do Sistema de Avaliação da Educação e do Ensino não Superior" (em vigor). Do ponto de vista normativo e legal, aprova o sistema de avaliação da educação do ensino não superior, tendo em vista, nomeadamente, a promoção de "uma cultura de melhoria continuada da organização, do funcionamento e dos resultados do sistema educativo e dos projetos educativos" (artigo $3^{\circ}$, alínea h). O mesmo diploma estrutura o processo de avaliação na autoavaliação, a realizar em cada escola, e na avaliação externa. A autoavaliação ou avaliação interna tem carácter obrigatório (artigo $6^{\circ}$ ) e "deve conformar-se a padrões de qualidade devidamente certificados" (artigo $7^{\circ}$ ). Neste quadro legal, ressalta a necessidade de não se "descurar as competências dos avaliadores"7;

${ }^{6}$ Este despacho clarifica que a retenção deve constituir uma medida pedagógica de última instância, depois de esgotado o recurso a atividades de recuperação desenvolvidas ao nível da turma e da escola. Deste modo, este despacho aponta para a necessidade de reorganização do trabalho escolar, levando a cabo medidas de diferenciação pedagógica, nomeadamente através de (i) planos de recuperação dirigidos a alunos a quem se detete no final do $1^{\circ}$ período dificuldades de aprendizagem; (ii) planos de acompanhamento a alunos objeto de retenção e (iii) planos de desenvolvimento para alunos que revelem capacidades excecionais de aprendizagem durante o $1^{\circ}$ período.

7 Esta Lei, em vigor, e contemplada na nossa análise empírica, estipula os seguintes objectivos: "a) Promover a melhoria da qualidade do sistema educativo, da sua organização e dos seus níveis de eficiência e eficácia, apoiar a formulação e o desenvolvimento das políticas de educação e formação e assegurar a disponibilidade de informação de gestão daquele sistema; b) Dotar a administração educativa local, regional e nacional, e a sociedade em geral, de um quadro de informações sobre o funcionamento do sistema educativo, integrando e contextualizando a interpretação dos resultados da avaliação; c) Assegurar o sucesso educativo, promovendo uma cultura de qualidade, exigência e responsabilidade nas 
- A nível do regime de autonomia administração e gestão dos estabelecimentos públicos da educação pré -escolar e dos ensinos básico e secundário, com o Decreto-lei n. ${ }^{\circ}$ 75/2008, de 22 de Abril, que estipula no seu art. $^{\circ}$ 8, p. 2 que: "A extensão da autonomia depende da dimensão e da capacidade do agrupamento de escolas ou escola não agrupada e o seu exercício supõe a prestação de contas, designadamente através dos procedimentos de autoavaliação e de avaliação externa".

Em 2008 e 2009, é colocada a ênfase sobre avaliação de desempenho dos professores aprovada pelo decreto regulamentar $n^{\circ}$ 2/2008 de 10 de Janeiro, na sequência da alteração do Estatuto da Carreira Docente pelo decreto-lei no 15/2007 de 19 de Janeiro. Através deste decreto a carreira de docente divide-se em duas categorias, professor titular e professor. O professor titular desempenhava algumas funções específicas, que anteriormente eram passíveis de serem desempenhadas por qualquer professor, como por exemplo coordenador de departamento curricular, ao qual competirá a tarefa de avaliar os professores que integram o órgão que coordena $\left(\operatorname{art}^{\circ}\right.$ $\left.43^{\circ}, n^{\circ} 2, a\right)$.

O Decreto-Lei n. ${ }^{\circ}$ 55/2009, de 2 de Março estabelece o regime jurídico aplicável à atribuição e ao funcionamento dos apoios no âmbito da ação social escolar. Uma vez que o PISA 2006 chama a atenção para “o desnível da distribuição socioeconómica”, o presente Decreto-Lei aplica-se às crianças e aos alunos que frequentem a educação pré escolar e os ensinos básico e secundário em estabelecimentos de ensino públicos, ou particulares e cooperativos em regime de contrato de associação.

O Decreto-Lei n. ${ }^{\circ} 3 / 2008$, de 7 de janeiro estabelece objetivos, enquadramento e princípios orientadores dos apoios especializados a prestar na educação pré-escolar e nos ensinos básico e secundário dos sectores público, particular e cooperativo, visando a criação de condições para a adequação do processo educativo às necessidades educativas especiais dos alunos com limitações significativas ao nível da atividade e da participação num ou vários domínios de vida, decorrentes de alterações funcionais e

escolas; d) Permitir incentivar as acções e os processos de melhoria da qualidade, do funcionamento e dos resultados das escolas, através de intervenções públicas de reconhecimento e apoio a estas; e) Sensibilizar os vários membros da comunidade educativa para a participação activa no processo educativo; f) Garantir a credibilidade do desempenho dos estabelecimentos de educação e de ensino; g) Valorizar o papel dos vários membros da comunidade educativa, em especial dos professores, dos alunos, dos pais e encarregados de educação, das autarquias locais e dos funcionários não docentes das escolas; h) Promover uma cultura de melhoria continuada da organização, do funcionamento e dos resultados do sistema educativo e dos projectos educativos; i) Participar nas instituições e nos processos internacionais de avaliação dos sistemas educativos, fornecendo informação e recolhendo experiências comparadas e termos internacionais de referência". 
estruturais, de carácter permanente, resultando em dificuldades continuadas ao nível da comunicação, da aprendizagem, da mobilidade, da autonomia. Deste modo estes apoios especializados podem incluir a adaptação de estratégias, recursos, conteúdos, processos, procedimentos e instrumentos, bem como a utilização de tecnologias de apoio. Portanto, não se trata só de medidas para os alunos, mas também de medidas de mudança no contexto escolar que devem propiciar a qualidade em educação.

E, com o Decreto-Lei n. ${ }^{\circ}$ 220/2009, de 8 de Setembro definem-se as condições necessárias à obtenção de habilitação profissional para a docência nos domínios de habilitação que não estavam abrangidos pelo Decreto -Lei n. ${ }^{\circ}$ 43/2007, de 22 de Fevereiro, e determina-se, ao mesmo tempo, que a posse deste título constitui condição indispensável para o desempenho docente nos ensinos público, particular e cooperativo e nas áreas curriculares ou disciplinas abrangidas por cada domínio.

Outras medidas legislativas foram tomadas em Portugal no sentido de alcançar os objetivos definidos pela comunidade europeia nomeadamente no âmbito das escolas profissionais com a publicação do Portaria 550-C/2004, DR 119, Série I-B $1^{\circ}$ Suplemento, de 2004-05-21 - Ministério da Educação - Criação, organização e gestão do currículo, bem como a avaliação e certificação das aprendizagens dos cursos profissionais de nível secundário.

A transferência de competências para os municípios, que constam do DecretoLei n. ${ }^{\circ}$ 144/2008 de 28 de Julho, resulta de um consenso negocial entre o Governo e a Associação Nacional de Municípios Portugueses. Desta forma é transferido para os municípios o pessoal não docente das escolas básicas e da educação pré - escolar.

\section{Considerações Finais}

O processo de globalização e a crescente internacionalização, mesmo que parcial, dos sistemas educativos e das mudanças de regulação estatais, promoveram uma nova cultura institucional que assentou em dois vetores: o "universalismo" e o “isomorfismo" (TEODORO 2002, p. 67).

A União Europeia potenciou o espírito europeísta, recorrendo para isso a propostas no domínio cultural e educativo, com a livre circulação das pessoas e de bens e a noção de cidadania. Assim, constitui-se como mediador, veículo e autor de processos de globalização e definiu as ações legislativas que impôs aos diversos Estados-membros, para atingir as metas educativas. 
A avaliação, enquanto instrumento de homogeneização, está bem patenteada nos documentos de orientação do contexto internacional e da União Europeia e pode ser visível através das políticas que promoveram a competitividade económica e empresarial, num quadro de mudanças advindas da globalização que vieram reforçar a Europa do conhecimento.

A nova economia baseada no conhecimento parte da convição de que este é a chave da competitividade e do desenvolvimento económico e social europeu e que, por isso, deve ser avaliado. Com a tendência na Europa para a descentralização, ampliou-se a sensibilidade à avaliação no campo educativo. Por outro lado, as organizações educativas cada vez mais responsáveis por sua ação encontram meios de conhecer em profundidade os resultados da avaliação. A avaliação responde ao mesmo tempo a uma procura de transparência e de informação sobre o Sistemas Educativos emanadas das famílias, das empresas e das coletividades públicas que sentem necessidade de pilotagem e de regularização.

No contexto de Portugal, após a instauração do regime democrático, foi sujeita as sucessivas reformas da educação pública, em tempo de globalização, que acabou por produzir algumas fragilidades ao nível das decisões de política educativa. O Estado português interpretou a competitividade educacional, como muitos outros países, inspiradas pelas reformas dos governos. Neste sentido, promoveu uma melhoria continuada da organização, do funcionamento e dos resultados do sistema educativo e participou nas instituições e nos processos internacionais de avaliação dos sistemas educativos, fornecendo informação e recolhendo experiências comparadas e termos internacionais de referência.

\section{REFERÊNCIAS}

AFONSO, J. Políticas Educativas e Avaliação Educacional. Para uma análise sociológica da reforma educativa em Portugal (1985-1995). Braga: Universidade do Minho. 1998.

AFONSO, J. Estado, Globalização e Políticas Educacionais: elemento para uma agenda de investigação. Revista Brasileira da Educação nº 22 - pp. 35-46. 2003.

ALVES, $\mathrm{P}$ \& MACHADO, O pólo de excelência Caminhos para a avaliação de professores. Porto: Areal Editores. 2010. 
ANTUNES, F Globalização e Europeização das Políticas Educativas Percursos, Processos e Metamorfoses. Sociologia, Problemas e Práticas, n. ${ }^{\circ}$ 47,pp.125-143. 2005.

ANTUNES, F. Políticas Educativas Nacionais e Globalização. Novas Instituições e Processos Educativos. Braga: UM/IEP. 2004a.

AZEVEDO, J. O Ensino Secundário na Europa. Porto: Asa. 2000.

BARROSO, J. "Regulação e desregulação nas políticas educativas: tendências emergentes em estudos de educação comparada". In J. Barroso (org.), A Escola Pública. Regulação, Desregulação e Privatização. Porto: Asa.2003, pp.19- 48..

CANÁRIO, R. O que é a Escola? Um ‘Olhar’ Sociológico. Porto: Porto Editora. 2005.

CARNEIRO, R. 2020: 20 anos para vencer 20 décadas de atraso educativo: síntese do estudo. In: CARNEIRO, R.\&CARAÇA, J.\& SÃO PEDRO, M. (Coord.). O futuro da educação em Portugal: tendências e oportunidades; um estudo de reflexão prospetiva. Lisboa: Ministério da Educação. v.1, 2000.

CASTELlS, M. A Era da informação: Economia, Sociedade e Cultura. Vol. $I-A$ sociedade em rede. Lisboa: Fundação Calouste Gulbenkian. 2005.

DALE, R. Globalização e educação: demonstrando a existência de uma 'cultura educacional mundial comum' ou localizando uma 'agenda globalmente estruturada para a educação? Educação, Sociedade Campinas, vol .25, n. ${ }^{\circ}$ 87, pp. 423-460. Mangualde: Edições Pedago. 2004.

DALE, R. Globalization: a new world for comparative education? In: SCHRIEWER, J. (org.). Discourse and comparative education. Berlin: Peter Lang. 1998.

MARCONDES, M. Avaliação Educacional em Portugal e no Brasil: Politicas e Práticas no Ensino Secundário e Médio. Braga: Universidade do Minho. 2004.

NEVES, C. As Organizações Internacionais e a Avaliação dos Sistemas de Educação e Formação: análise crítica e comparativa. Revista Europeia de Formação Profissional. n 45 , pp78-98. 2008.

NÓVOA, A. As Ciências da Educação e os Processos de Mudança in B.CAMPOS; A. NÓVOA; J. PONTE; E. B. SANTOS. Ciências da educação e mudança. Porto: Sociedade Portuguesa de Ciências da Educação. 1991, pp. 17-67.

PORTUGAL. Decreto Regulamentar n. 2/2008 de 10 de janeiro Diário da República, no 7 I Série - Avaliação do desempenho dos docentes integrados na carreira, 2008.

PORTUGAL. Decreto-Lei n. ${ }^{\circ} 115-A / 98$, de 4 de maio, Diário da República, n. ${ }^{\circ}$ 102, I Série A - Regime de Autonomia, Administração e Gestão das Escolas,1998.

PORTUGAL. Decreto-Lei n. ${ }^{\circ}$ 129/93, de 22 de abril, Diário da República n. ${ }^{\circ}$ 94, I Série-A Estabelece os princípios da Política de Acção Social no Ensino Superior,1993.

PORTUGAL. Decreto-Lei n. ${ }^{\circ} 144$ /2008 de 28 de Julho, Diário da República, nº 144, Série-A - Desenvolve o quadro de transferência de competências para os municípios em 
matéria de educação, de acordo com o regime previsto na Lei n. ${ }^{\circ}$ 159/99, de 14 de Setembro, 2008.

PORTUGAL. Decreto-Lei n. ${ }^{\circ} 15 / 2007$ de 19 de janeiro, Diário da República n. 38 Série I-A - novo estatuto carreira docente, 2007.

PORTUGAL. Decreto-Lei n. ${ }^{\circ}$ 172/91, de 10 de maio, Diário da República, n. ${ }^{\circ}$ 107, I Série A - Ordenamento Jurídico da Direcção, Administração e Gestão dos Estabelecimentos de Ensino da Educação Pré-escolar e dos Ensinos Básico e Secundário, 1991.

PORTUGAL. Decreto-Lei n. ${ }^{o}$ 209/2002, de 17 de outubro, Diário da República, n. ${ }^{\circ}$ 240, I Série-A - Aprova a Organização Curricular do Ensino Básico, Estabelecendo os Princípios orientadores da Organização e da Gestão, 2002.

PORTUGAL. Decreto-Lei n. ${ }^{\circ}$ 220/2009 de 8 de setembro, Diário da República, $\mathbf{n}^{\mathbf{0} 174}$, I, Série-A. Define as condições necessárias à obtenção de habilitação profissional,2009.

PORTUGAL. Decreto-Lei n. ${ }^{\circ}$ 3/2008 de 18 de Janeiro, Diário da República, no $\mathbf{n}^{\mathbf{1 3}}$, I Série-A - Alterações à lei no 30/2002, de 20 de dezembro, 2008.

PORTUGAL. Decreto-Lei n. ${ }^{\circ}$ 37/94, de 11 de novembro, Diário da República n. ${ }^{\circ}$ 261, I Série-A Aprova o Estatuto do Ensino Superior Particular e Cooperativo, 1994.

PORTUGAL. Decreto-Lei n. ${ }^{\circ}$ 55/2009 de 2 de março, Define o regime jurídico para a atribuição e funcionamento dos apoios no âmbito da Acão Social Escolar (ASE) e vem reforçar e alargar a política de apoio às famílias no âmbito socioeducativo, 2009.

PORTUGAL. Decreto-Lei n. ${ }^{\circ}$ 75/2008 de 22 de abril, Diário da República, no 79, Série-A - Regime de Autonomia, Administração e Gestão das Escolas, 2008.

PORTUGAL. Lei n..$^{\circ}$ 24/99, de 22 de abril, Diário da República n. ${ }^{\circ}$ 94, I Série-A Alteração ao Decreto-Lei n. ${ }^{\circ} 115-A / 98$, de 4 de Maio,1999.

PORTUGAL. Lei no 31/2002 de 20 de dezembro, Diário da República n. ${ }^{\circ}$ 294, I SérieA - Aprova o sistema de avaliação da educação e do ensino não superior,2002.

RODRIGUES, P. A Avaliação Curricular. In ESTRELA, A; NÓVOA, A. (org.) Avaliações em educação: novas perspectivas. Porto: Porto Editora. 1993, pp. 15-76.

ROGGERO, P. Avaliação dos Sistemas Educativos nos Países da União Europeia: De uma Necessidade Problemática a uma Prática Complexa Desejável. Ecos Revista Científica. S. Paulo: Centro Universitário Nove de Julho vol 4, nº 2, pp. 31-46. 2002.

SANTOS, A. Por uma Política de Ideias em Educação. Porto: ASA. 2002.

SANTOS, B. Os Processos de Globalização. In Santos, B. (org.). Globalização, Fatalidade ou Utopia? Porto. Edições Afrontamento. 2001, pp. 33- 106.

STOER, S. \& CORTESÃO, L. Levantando a Pedra. Da Pedagogia Inter/Multicultural às Politicas Educativas numa época de Transnacionalização. Porto: Afrontamento. 1999. 
TEODORO, A. As Políticas de Educação em discurso directo (1955-1995). Lisboa: Instituto de Inovação Educacional. 2002.

TEODORO, A. Organizações internacionais e políticas educativas nacionais: emergência de novas formas de regulação transnacional, ou uma globalização de baixa intensidade, in STOER; CORTESÃO \& Correia (orgs.). Transnacionalização da Educação. Porto: Edições Afrontamento. 2001.

VASCO, G. Sobre o Financiamento da Educação: condicionantes globais e realidades nacionais" Revista Lusófona de Educação, n.13, p. 49-80, 2009.

\section{Como referenciar este artigo}

SANTOS, Correia Paulino. As mudanças educativas proporcionadas pelas políticas de avaliação. Revista Ibero-Americana de Estudos em Educação, Araraquara, v. 11, n. 4, p. 1885-1905, 2016. Disponível em: 〈http://dx.doi.org/10.21723/riaee.v11.n4.6573〉. E-ISSN: 1982-5587.

Submetido em: janeiro/2014

Aprovação final em: julho/2016 